BMJ Open Sport \& Exercise Medicine

\title{
Italian consensus statement (2020) on return to play after lower limb muscle injury in football (soccer)
}

Gian Nicola Bisciotti, ${ }^{1}$ Piero Volpi, ${ }^{2,3}$ Giampietro Alberti, ${ }^{4}$ Alessandro Aprato, ${ }^{5}$ Matteo Artina, ${ }^{6}$ Alessio Auci, ${ }^{7}$ Corrado Bait, ${ }^{8}$ Andrea Belli, ${ }^{3}$ Giuseppe Bellistri, ${ }^{3}$ Pierfrancesco Bettinsoli, ${ }^{9}$ Alessandro Bisciotti, ${ }^{10}$ Andrea Bisciotti, ${ }^{10}$ Stefano Bona, ${ }^{2}$ Marco Bresciani, ${ }^{11}$ Andrea Bruzzone, ${ }^{12}$ Roberto Buda, ${ }^{13}$ Michele Buffoli, ${ }^{14}$ Matteo Callini, ${ }^{15}$ Gianluigi Canata, ${ }^{16,17}$ Davide Cardinali, ${ }^{10}$ Gabriella Cassaghi, ${ }^{10}$ Lara Castagnetti, ${ }^{2}$ Sebastiano Clerici, ${ }^{18}$ Barbara Corradini, ${ }^{10}$

Alessandro Corsini (D) , ${ }^{3}$ Cristina D'Agostino, ${ }^{2}$ Enrico Dellasette, ${ }^{3}$ Francesco Di Pietto, ${ }^{19}$ Drapchind Enrica, ${ }^{10}$ Cristiano Eirale, ${ }^{1,20}$ Andrea Foglia, ${ }^{21}$ Francesco Franceschi, ${ }^{22}$ Antonio Frizziero, ${ }^{23}$ Alberto Galbiati, ${ }^{3}$ Carlo Giammatei, ${ }^{24}$ Philippe Landreau, ${ }^{25}$ Claudio Mazzola ${ }^{26}$ Biagio Moretti, ${ }^{27}$ Marcello Muratore, ${ }^{3}$ Gianni Nanni, ${ }^{28,29}$ Roberto Niccolai, ${ }^{3}$ Claudio Orizio, ${ }^{30}$ Andrea Pantalone, ${ }^{31,32}$ Federica Parra,${ }^{10}$ Giulio Pasta,${ }^{33,34}$ Paolo Patroni, ${ }^{35}$ Davide Pelella, ${ }^{3}$ Luca Pulici (1) , ${ }^{3}$ Alessandro Quaglia, ${ }^{2,3}$ Stefano Respizzi, ${ }^{2}$ Luca Ricciotti, ${ }^{10}$ Arianna Rispoli, ${ }^{10}$ Francesco Rosa, ${ }^{2}$ Alberto Rossato, ${ }^{36}$ Italo Sannicandro, ${ }^{37}$ Claudio Sprenger, ${ }^{3}$ Chiara Tarantola, ${ }^{10}$ Fabio Gianpaolo Tenconi, ${ }^{38}$ Giuseppe Tognini, ${ }^{39}$ Fabio Tosi, ${ }^{3}$ Giovanni Felice Trinchese, ${ }^{40}$ Paola Vago, ${ }^{41}$ Marcello Zappia ${ }^{42}$ Zarko Vuckovich, ${ }^{1}$ Raul Zini, ${ }^{43}$ Michele Trainini, ${ }^{44}$ Karim Chamari ${ }^{1,45}$

To cite: Bisciotti GN, Volpi P, Alberti G, et al. Italian consensus statement (2020) on return to play after lower limb muscle injury in football (soccer). BMJ Open Sport \& Exercise Medicine 2019;5:e000505. doi:10.1136/ bmjsem-2018-000505

Accepted 27 July 2019

Check for updates

\section{(C) Author(s) (or their} employer(s)) 2019. Re-use permitted under CC BY-NC. No commercial re-use. See rights and permissions. Published by BMJ.

For numbered affiliations see end of article.

\section{Correspondence to} Dr Alessandro Corsini,F.C. Internazionale Milano, Milano, Milano, Italy; sirconi@gmail.com

\section{ABSTRACT}

Return to play (RTP) decisions in football are currently based on expert opinion. No consensus guideline has been published to demonstrate an evidence-based decisionmaking process in football (soccer). Our aim was to provide a framework for evidence-based decision-making in RTP following lower limb muscle injuries sustained in football. A 1-day consensus meeting was held in Milan, on 31 August 2018, involving 66 national and international experts from various academic backgrounds. A narrative review of the current evidence for RTP decision-making in football was provided to delegates. Assembled experts came to a consensus on the best practice for managing RTP following lower limb muscle injuries via the Delphi process. Consensus was reached on (1) the definitions of 'return to training' and 'return to play' in football. We agreed on 'return to training' and RTP in football, the appropriate use of clinical and imaging assessments, and laboratory and field tests for return to training following lower limb muscle injury, and identified objective criteria for RTP based on global positioning system technology. Level of evidence IV, grade of recommendation $D$.

\section{INTRODUCTION}

In professional football (soccer), injuries to the hamstring, quadriceps femoris, adductors and soleus-gastrocnemius account for $80 \%-90 \%$ of all muscle injuries. ${ }^{1-3}$ Teams
How might it impact on clinical practice in the future?

Our findings represent a reference from Italian experts and may help inform practitioners looking for guidance when making RTT and RTP decisions following lower limb muscle injury in football.

- Further research is required to determine the reliability and validity of the tests recommended due to a lack of available evidence.

- We acknowledge that our consensus, despite engaging a large number of experts, provides 'level 4 ' evidence.

- We both anticipate and welcome constructive discussion on areas where others may have data we have missed, opinions that diverge from ours and suggestions for new investigations.

- We appreciate that the overarching goal of sports and exercise medicine research is to improve RTT and RTP for football players and all sportsmen and sportswomen.

that minimise time-loss injuries often achieve greater league success. ${ }^{4-7}$ The return to play (RTP) decision-making process in professional football involves multiple stakeholders, including the individual player, the sports medicine team, the coaching staff and the 
technical/performance teams. All must combine effectively to facilitate a successful RTP. ${ }^{8-12}$

There is very little research evidence to support RTP decision-making in football, so RTP decision-making process has been based on expert advice (level IV evidence, grade D, using the Grading of Recommendations Assessment, Development and Evaluation [GRADE] framework). ${ }^{13}$ Today there is no consensus conference specifically focused only on RTP decision-making for lower limb muscle injuries in football. Muscle injuries represent a heterogeneous group including several muscle groups with varying anatomical location, size and biological responses (eg, healing time). ${ }^{11415}$ RTP decision should be based on the specific muscle injured. We propose clinical guidelines, imaging protocols, and laboratory and field tests for clinicians to consider for each muscle group.

\section{ITALIAN CONSENSUS CONFERENCE ON RTP AFTER LOWER LIMB MUSCLE INJURY IN FOOTBALL}

The Italian Consensus Conference (CC) (referred to here as 'Conference') on RTP after lower limb muscle injury in football was organised by the Italian Society of Arthroscopy in Milan. The meeting was held on 31 August 2018, with the participation of 66 national and international experts covering several disciplines, including the following:

- Orthopaedic surgeons (19).

- Sports physicians (7).

- Radiologists (5).

- Rehabilitation physicians (3).

- Sport physiologists (2).

- General surgeons (2).

- Family physicians (2).

- Physiotherapists (10).

- Physical trainers (15).

- Psychologist (1).

The selection of experts was based on pre-eminence in at least one of three criteria: (1) Hirsch Index, (2) number of publications concerning muscle injuries in football, and (3) clinical evaluation, medical treatment and rehabilitation of muscle injuries in football. The experts did not represent any commercial organisations at the time of the consensus meeting. All those who participated in the CC are included as authors of this report. Two authors (KC and ZV), although not present at CC, provided intellectual contributions to the study.

This paper represents the synthesis of the Italian Conference on RTP following lower limb muscle injury in football. The complete document (90 pages in Italian) can be found on the official website of the Italian Society of Arthroscopy (www.siaonline.net).

\section{CONSENSUS CONFERENCE NARRATIVE REVIEW PROCESS}

Prior to the Conference, two senior authors (GNB and PV) performed a narrative review of RTP decision-making literature in sport and in football specifically. The review process was conducted as follows:

\section{Box 1 Inclusion and exclusion criteria}

\section{Inclusion criteria}

- Patient and problem: randomised controlled trials, cases series studies and consensus statement investigating lower muscle injuries in sport.

- Intervention: conservative treatment of lower muscle injuries.

- Comparator: comparison between different types of muscle injury classification and different types of conservative treatments.

- Outcome: time lost to injury, level of return to play, complications and sequelae.

\section{Exclusion criteria}

- Patient and problem: randomised controlled trials, case series and consensus statements that investigated lower muscle injuries in a non-sporting population.

- Intervention: surgical treatment of lower muscle injuries.

- Comparison: comparison between conservative and surgical treatments.

- Outcome: unspecified outcome of time lost to injury, level of return to play, complications and sequelae.

- An independent search was performed by both authors, with no language limitation applied.

- The databases searched were Medline, EMBASE, Excerpta Medica, Cochrane Central Register of Controlled Trials and the Cochrane Database of Systematic Reviews. Grey literature (ie, conferences, abstracts, thesis and unpublished reports) was not considered.

- Studies that did not meet our inclusion criteria were excluded. The inclusion and exclusion criteria are shown in box 1 .

The authors provided a summary document divided into two sections:

1. RTP decision general principles (in sport, not only in football; see inclusion criteria in box 1).

2. RTT and RTP decision-making following lower limb muscle injuries in football.

The document was presented to each expert a week ahead of the Conference and was considered the starting point for our discussion. The two senior authors facilitated (GNB) and chaired (PV) the Conference.

\section{CONSENSUS CONFERENCE STATEMENT}

Having outlined the background to the consensus statement and the methods, we now share our key findings in two sections.

Section 1 of our consensus reports the general principles of RTP decision under five subheadings:

- Terminology relating to RTP.

- Return to training (RTT): decision-making process.

- RTP: decision-making process.

- Imaging: what role should it play when clinicians make RTT and RTP decisions.

- The biopsychosocial model and RTP decisions. 
Table 1 Mean (SD) of voting rounds for section 1 (RTP decisions general principles)

\begin{tabular}{llllll}
\hline & Voting & Voting & Voting & Voting & Voting \\
$\mathbf{1}$ & $\mathbf{2}$ & $\mathbf{3}$ & $\mathbf{4}$ & $\mathbf{5}$ \\
\hline Average score & 9.76 & 9.76 & 9.80 & 9.72 & 9.96 \\
SD & 0.33 & 0.33 & 0.30 & 0.35 & 0.32 \\
\hline
\end{tabular}

RTP, return to play.

Our consensus 'decision-making process' refers to the evidence-based criteria outlined to support decisions on both RTT and RTP. ${ }^{16} 17$

Section 2 of our consensus provides guidance on RTT and RTP decision following four specific lower limb muscle injuries in football. We cover decisions on both RTT and RTP following:

- Hamstring injuries.

- Quadriceps injuries.

- Adductor injuries.

- Soleus-gastrocnemius injuries.

The agreements and guidance presented were the result of a Delphi process. A written outline for each section was presented by the facilitator (GNB), followed by a plenary discussion conducted by the chairman (PV). Acceptance of a consensus statement was approved by a majority vote.

The Conference participants voted using a Likert scale of $0-10$, where 0 reflected complete disagreement, 5 neither agreement nor disagreement, and 10 complete agreement. Clarification and debate continued until a mean score of $>7.5$ was reached. ${ }^{15}{ }^{18-20}$ For section 1, we required five rounds of votes, while for section 2 four rounds to reach consensus. Amendments were made between each voting round following discussion among the Conference group. Consensus was reached in all cases (ie, for each voting round, a mean score of $>7.5$ was reached). The voting results are shown in tables 1 and 2 .

\section{SECTION 1: RTP DECISION GENERAL PRINCIPLES Terminology of RTP}

The term RTP was defined by the consensus statement developed by the American Academy of Orthopaedic Surgeons and the American College of Sports Medicine as follows:

The decision-making process of returning an injured or ill athlete to practice or competition. This ultimately leads to medical clearance of an athlete for full participation in sports. ${ }^{21-23}$

This definition implicitly means a return to 'full training and competition availability'. However, in football, RTP is complex and often involves a period of progressive reintegration, where a player is not necessarily a full participant in all team activities. This period varies on factors such as the type of injury and the overall amount of time out of full training. During the reintegration period, the player
Table 2 Mean (SD) of voting rounds for section 2 (RTT and RTP decision-making following lower limb muscle injuries in football)

\begin{tabular}{lllll}
\hline & & & & Voting \\
& Voting 1 & Voting 2 & Voting 3 & $\mathbf{4}$ \\
\hline Average score & 9.24 & 9.64 & 9.54 & 9.72 \\
SD & 0.49 & 0.39 & 0.43 & 0.35 \\
\hline
\end{tabular}

RTP, return to play; RTT, return to training.

may be subjected to constraints concerning both the intensity and amount of training load performed. ${ }^{24} 25$

The CG considered it necessary to introduce a clarification, in accordance with the 2016 consensus statement on the return to sport. ${ }^{8}$ We define the term 'return-to-training' as beginning when the player is partially reintegrated into the team, and define the term 'return to play'as beginning when a player has made a full return to unrestricted availability in training and competition.

In summary, the concept of RTT is linked to 'return to sports practice/training with possible restrictions', while RTP is linked to the concept of 'return to training and competition without restriction'. We underline that RTT and RTP are based on different decision-making criteria. RTT is based on clinical-functional criteria, whereas RTP is based on functional-performance criteria. The RTP criteria have an added layer of complexity as decision-making crosses from the responsibility of medical team to the performance team. ${ }^{24}$

\section{The RTT decision-making process}

RTT decisions must be supported by clinical assessment and imaging and functional tests based on 'injury-dependent criteria'. The following points must be identified and followed for each type of muscle injury:

- Identification of appropriate clinical tests dependent on the type of muscle injury. ${ }^{8}$

- Identification of appropriate imaging protocols dependent on the type of muscle injury. ${ }^{152425}$

- Identification of appropriate laboratory tests specific to the functional deficit for the type of muscle injury. ${ }^{26} 27$

- Identification of appropriate field tests specific to the functional deficit for the type of muscle injury. ${ }^{26} 27$

The test battery must account for the performance and related physiological demands of each player's field position. RTT decision-making process may need to be altered for primary time-loss or recurrent time-loss injury. ${ }^{8-10} 1617$

\section{The concept of 'tolerable risk' in RTT decision-making process}

Tolerable risk (TR) represents the maximum level of risk acceptable for different short-term and longterm outcomes associated with RTT. ${ }^{8-10} 2829$ TR is attributed equally to medical and technical staff, team management, and the player. TR is shared except in life-threatening situations (eg, concussion in which the player has a reduced level of consciousness/decision-making ability). Under such circumstances, the 

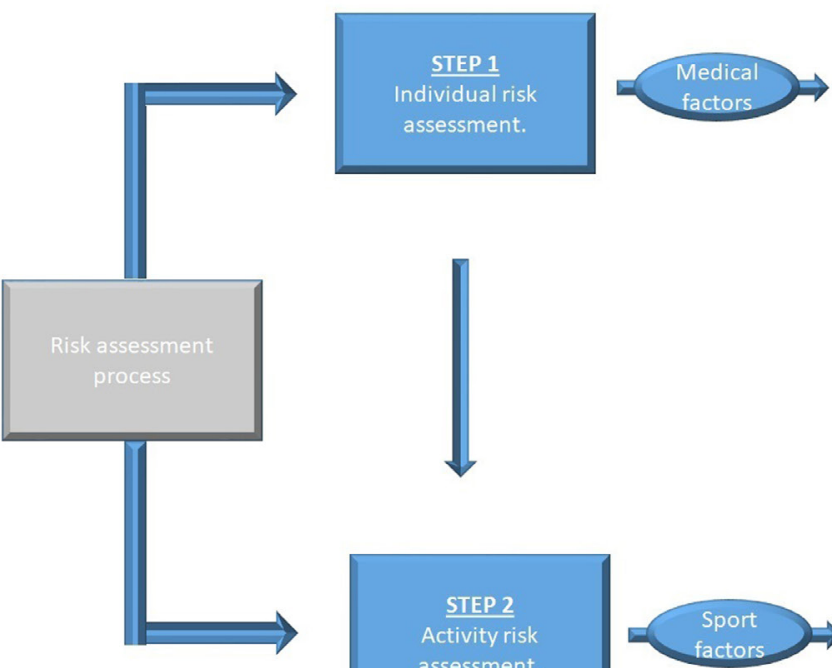

\section{Age, sex, ethnicity, BW}

Medical history (first injury /recurrence)

Typology of lesion (grade, anatomiclocation)

Clinical evaluation (signs and symptoms)

Imaging

Tests (laboratory and field tests)

Level of physical fitness

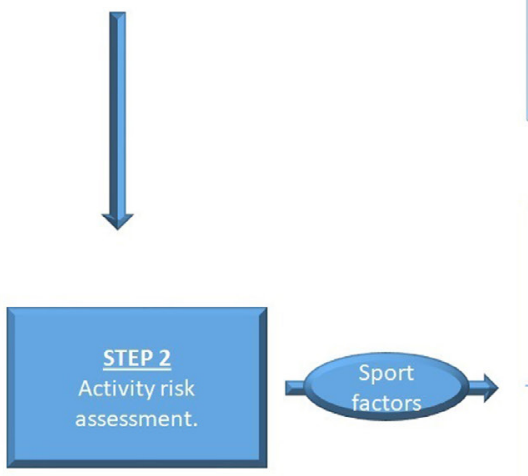

Psychological state

\section{Role (holder, reserve goalkeeper etc.)}

Limb dominance

Competitive level (professional, amateur)

Individual style of play (aggressive, ability to protect)

Psychological readiness sensation

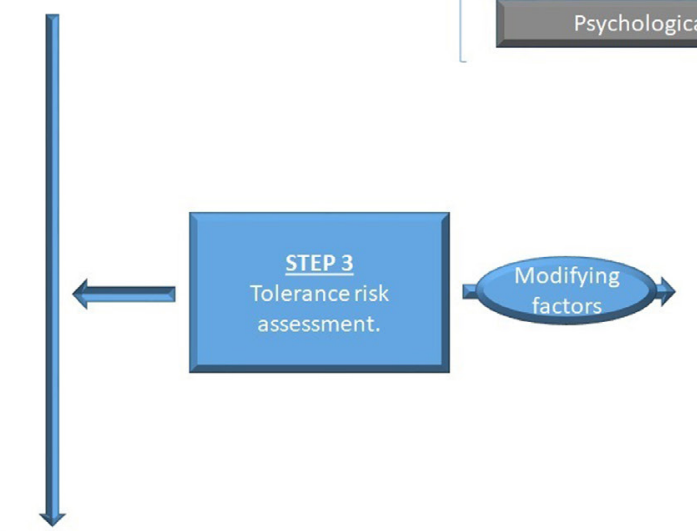

Importance of the match and period of the season

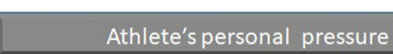

RETURN TO PLAY DECISION-MAKING PROCESS

Figure 1 Tolerance risk flow chart. The first step is the 'individual risk assessment', while the second step is the 'activity risk factors'. The first and second steps represent the 'risk assessment process'. The third step (tolerance risk assessment) influences the risk assessment process in the return to play decision-making process. BW, body weight.

sole and final decision of RTT depends entirely on the medical team assessment. TR is variable and dependent on the presenting situation. For example, TR may be considered greater in a cup final than in a friendly match. Furthermore, TR can be influenced by several factors, such as whether an injury is acute or an overuse injury; a first time injury or recurrence; by its degree of severity and anatomical location; by its type (ie, monoarticular muscle, biarticular muscle, myotendinous junction, in proximity to the central tendon and so on); and by biological, endocrine-metabolic and gender-related factors. TR may also need to take into account for economic evaluations; a typical example is when the player is directly involved in a market negotiation (ie, transfer). The tolerance risk flow chart is shown in figure 1 . In any case, it is important to underline that the medical staff has the responsibility to act in the best interests of the player's long-term health regardless of any contractual negotiation.

For player suffering from a muscle injury, TR is represented by the objective quantification of the maximum mechanical load that can be tolerated by the injured muscular tissues. TR must be based on the following:

- Clinical examination.

- Imaging.

- Functional tests.

The clinical examination is illustrated in section 2 . 
The basic principles of functional tests used in the RTT decisionmaking process

Functional tests must attempt to simulate real-time game situations that replicate the following ${ }^{28}$ :

- Forces required during muscle contraction.

- Speed required during movement.

- Power expressed during movement.

- Type of movement required (ie, specific or non-specific to the football model; eg, straight line running is a non-specific movement, while cutting during a run is a specific movement).

- Specificity of the required movement (ie, specific or non-specific in comparison with the movement/ movements that can cause a reinjury in the previously injured muscles; eg, a sprint is a specific risk movement for biceps femoris muscle injury, and kicking is a specific risk movement for rectus femoris muscle injury).

Objective criteria in the RTP decision-making process

Decisions for RTT and RTP should be based on objective criteria. The only subjective criteria that may be taken into account are the individual profiles (ie, the psychological state) of players. Clinical and functional investigations that are numerically quantifiable are preferred when making decision. In this context, a reported pain value, such as the Visual Analogue Scale, is acceptable. Indeed, pain is an essential parameter in the decision-making process. ${ }^{30-48}$ The presence of pain in the injured tissue area strongly suggests that healing is incomplete. For this reason, many authors underline the notion that RTT should be granted only on complete resolution of the presenting symptoms. ${ }^{36}$ 48-54

\section{The RTP decision-making process}

The RTP decision-making process is a judgement of whether the athlete is fit enough to resume full training without restriction, as well as ready to take part in competition. The decision-making process for RTP, which follows that of RTT, is an assessment based on a judgement of 'functionality' and 'performance capacity' rather than 'clinical-functional suitability'.

We considered the use of global positioning system (GPS) technology ${ }^{55}$ sufficient to inform objective criteria. Therefore, these recommendations are limited to teams who have access to GPS information. We encourage all professional teams to adopt GPS data collection.

We subdivided the fundamental points of the RTP decision into three evaluation categories:

- Quantitative evaluation (QNE).

- Qualitative evaluation (QLE).

- Parameter analysis (PA).

Quantitative evaluation

$\mathrm{QNE}^{25}{ }^{57-59}$ requires the analysis of speed (divided into six progressively increasing speed categories) recorded in the last period of preinjury training versus the same parameters recorded in the postinjury period to make an RTP judgement.

For each of the six categories of speed listed, the recorded data should account for the time spent and distance covered at the indicated velocity. Recordings should be taken in similar training environments (ie, do not compare possession-based play with shuttle runs). The categories are presented below.

- Walking (range $0-<5.4 \mathrm{~km} /$ hour).

- Jogging (range 5.5-<10.8 km/hour).

- Low speed running (range 10.9-<14.4km/hour).

- Intermediate speed running (range $14.5-<19.8 \mathrm{~km} /$ hour).

- High-speed running (range 19.9-<25.2 km/hour).

- Maximum speed running ( $\geq 25.2 \mathrm{~km} /$ hour$)$.

Qualitative evaluation

QLE is based on the analysis of metabolic power (MP) calculated with GPS technology. MP (expressed in W/ $\mathrm{kg}^{-1}$ ) represents the product of speed and acceleration in determining the intensity of running. ${ }^{57-59}$

The MP value can be calculated using the following formula ${ }^{57}$ :

\section{$\mathrm{MP}=\mathrm{CE} \bullet \mathrm{v}$}

where CE represents the energy cost of running at a constant speed (equal to $1 \mathrm{kcal} / \mathrm{kg} / \mathrm{km})^{59}$ and $\mathrm{v}$ is the athlete's instantaneous speed. Below is the division of MP into six progressively greater categories. MP is calculated by quantifying time spent in each MP category.

Low power $\left(0-<5 \mathrm{~W} \cdot \mathrm{kg}^{-1}\right)$.

- Intermediate power $\left(5.1-<10 \mathrm{~W} \cdot \mathrm{kg}^{-1}\right)$.

- High power $\left(10.1-<20 \mathrm{~W} \cdot \mathrm{kg}^{-1}\right)$.

- Higher power $\left(20.1-<25 \mathrm{~W}^{-\mathrm{kg}^{-1}}\right)$.

- Very high power $\left(25.1-<50 \mathrm{~W} \cdot \mathrm{kg}^{-1}\right)$.

- Maximum power $\left(\geq 50 \mathrm{~W} \cdot \mathrm{kg}^{-1}\right)$.

MP time values recorded in the last period of preinjury training are compared with the same parameters recorded postinjury to formulate the RTP judgement.

\section{Parameter analysis}

$\mathrm{PA}$ is based on a number of parameters recorded preinjury, including the following ${ }^{57-59}$ :

- Total distance covered during training (regardless of the run speed).

- Equivalent distance (ED). In football, energy expenditure is influenced by the accelerating and decelerating components of the activity ${ }^{58}$ ED corresponds to the distance that the athlete could theoretically cover if he ran, at constant speed, using the same total energy expenditure as that used during the game. The ED value can be calculated using the following formula ${ }^{57}$ :

$\mathrm{ED}=\mathrm{W} / \mathrm{Ecc}$ 
where $\mathrm{W}$ represents the energy cost expressed in $\mathrm{J} / \mathrm{kg}$, and Ecc is the energy cost of running in a straight line at constant speed on compact grassland (ie, $4.6 \mathrm{~J} / \mathrm{kg}$ ).

- Equivalent distance index (EDI). EDI represents the ratio between the value of ED and the distance actually covered by the player (RD) according to the following formula ${ }^{57}$ :

\section{$\mathrm{EDI}=\mathrm{ED} / \mathrm{RD}$}

- Anaerobic index (AI). AI represents the ratio between the energy cost beyond a certain metabolic threshold (ie, anaerobic threshold value or maximal aerobic speed value) and is calculated as follows ${ }^{57}$ :

\section{$\mathrm{AI}=\mathrm{Wtp} / \mathrm{W}$}

where Wtp represents the energy consumed beyond the metabolic threshold considered (anaerobic threshold or maximal aerobic speed) expressed in $\mathrm{J} / \mathrm{kg}$, and $\mathrm{W}$ is the total energy expenditure, also expressed in $\mathrm{J} / \mathrm{kg}$.

The evaluation of aerobic fitness in RTP decision-making process Many studies suggest a correlation between low aerobic fitness and increased risk of muscle injury. ${ }^{60-66}$ Injuries with greater time loss characterised by low-intensity physical activity are accompanied by a decrease in aerobic fitness. ${ }^{6}$ Suspension of high-intensity aerobic activity for 20 days or greater results in a significant decrease in $\mathrm{VO}_{2 \max }{ }^{67} 68$ Therefore, 20 days or greater of reduced aerobic activity should include an evaluation of $\mathrm{VO}_{2 \max }$ and/or the corresponding aerobic speed value ${ }^{69}$ assessed by an incremental speed run test. We suggest evaluating aerobic fitness during the RTP period by a valid test for determining $\mathrm{VO}_{2 \max }{ }^{70-74}$

The monitoring of acute and chronic load in the RTP decisionmaking process

The over-riding priority of RTP period is to avoid reinjury. ${ }^{8-10}$ Monitoring of the training load, that is, the 'acute load', in relation to the preceding four training loads, that is, the so-called 'chronic load', allows the 'acute versus chronic workload' ratio (ACWR) to be calculated. ${ }^{75}$ Use of ACWR is still debated and therefore it may be necessary to update load calculations based on future best practice guidelines. ${ }^{7677}$ However, we consider the calculation of ACWR useful in managing progressive increases in training load, which may reduce the risk of reinjury. We strongly advise that ACWR assessment becomes an integral part of RTP decisions.

\section{The role of imaging in the RTT and RTP decision-making process}

The value of imaging during decision to return a player to sport is debated. ${ }^{16-83}$ In RTP cases $29-49$ days after a muscle injury, between $50 \%$ and $90 \%$ of athletes still show an abnormal MRI signal (ie, hyperintensity of the injured area) ${ }^{84-86}$ Furthermore, an abnormal ultrasound
(US) signal may be obtained in $32 \%$ of examinations. ${ }^{84}$ On average, the area under the anomalous MRI signal, at the time of RTP, ranged from $20 \%$ to $28 \%$ of the area measured at the baseline, that is, at the time of the injury. ${ }^{86}$ Both the MRI and the US signals normalised after an average of 6 months. ${ }^{84-86}$ Several studies of postlesion tissue at the time of RTP demonstrate that $34 \%$ of athletes exhibit a low-intensity MRI signal, indicative of the formation of fibrotic scar tissue.$^{8487}$ Despite persistent alteration, the percentage of reinjuries was less than $2 \% \cdot{ }^{84-86}$ The presence of abnormalities on MRI and US during this period may be explained by the greater number of the ionic interactions of immature collagen formed during the early stage of muscle healing. The conversion of these weaker bonds to stronger covalent bonds, during post-translational modifications of the constituent amino acids, may require longer periods of up to 6 months depending on the extent of the injury. ${ }^{84}$

Therefore, in respect of imaging, this consensus specifies the following:

- RTT decision-making process does not necessarily require a total resolution of MRI and US area of signal alteration. ${ }^{84-86}$

- In MRI, a signal alteration (hyperintensity zone in fluid-sensitive sequences) decreased by at least $70 \%$ in comparison with the baseline signal alteration is acceptable for RTT. ${ }^{85} 8689$

- The presence of an extensive area of low signal intensity, indicative of fibrotic scar tissue, must be interpreted as a risk factor for reinjury. ${ }^{83} 8687$ However, attention must be paid to the fact that a haemosiderin deposition, following haemorrhage, can mimic the formation of fibrotic tissue. ${ }^{89}$

- Given its greater sensitivity and the greater tissue contrast gradient, MRI is preferable to US when making RTT decisions. ${ }^{84} 89$

\section{The biopsychosocial model}

RTT and RTP decision-making processes are heavily influenced by the psychosocial context within which they occur. ${ }^{80-93}$ Not taking psychosocial factors into account can lead to the loss of valuable objective information being missed. Psychological factors include apprehension, fear or anxiety. In addition to negatively interfering with performance, these parameters represent a risk factor for reinjury. ${ }^{37} 54$ 94-97 Therefore, we specified the following:

- During RTT and RTP decisions should take into account the psychological state of the athlete. ${ }^{3794-96}$

- Individuals such as the coach, technical staff and others may exert pressure on the RTT and RTP decision-making process. ${ }^{29} 434494$ 98-103 A potential conflict of interest exists between the athlete's needs and wishes of the coach, technical staff and/or the management team of the club. ${ }^{100} 104105$ We recommend all stakeholders avoid external pressures to maintain maximum objectivity during RTT and RTP decisions. 
- The decision-making process must be based on a continual exchange of information, between all stakeholders. This should allow for reformulation/revision of the rehabilitation plan where necessary. ${ }^{8-10}$

- The RTT and RTP decision-making process must be based on a continuum that runs parallel to the rehabilitation process. Isolated decisions regarding RTT and RTP that are not part of the rehabilitation process are to be avoided. ${ }^{8-10}$

- The RTT and RTP decision-making process must be player-centred. The central role of the player/patient is to be respected by taking the following into account:

1. The short-term, medium-term and long-term health risks associated with RTT and RTP.

2. The role of player/patient as an active 'decision maker' when deciding whether to RTT or RTP.

\section{SECTION 2: RTT AND RTP DECISION-MAKING FOLLOWING LOWER LIMB MUSCLE INJURIES IN FOOTBALL}

Hamstrings, quadriceps, adductors and soleus-gastrocnemius muscles account for $80 \%-90 \%$ of all football muscle injuries. ${ }^{1-3}$ Each muscle group was reviewed and reported under five subheadings:

- Epidemiology.

- Clinical and imaging assessments for RTT.

- Laboratory tests for RTT.

- Field tests for RTT.

- RTP tests.

\section{RTT and RTP decisions following hamstring injuries}

\section{Epidemiology}

Hamstring injuries are the most frequent injury in football and represent about $17 \%$ of all football injuries. ${ }^{106}$ A professional football team incurs an average of 10 hamstring injuries per season. ${ }^{67}$ This results in an average of 90 days of time lost to injury, and on average between 15 and 21 matches lost per team per season. The incidence of hamstring injuries ranges from 0.87 to 0.96 per 1000 hours of exposure (training and match). ${ }^{6}$

\section{Clinical and imaging assessments for RTT}

The following are our recommendations for clinical and imaging assessments for RTT following hamstring injury:

\section{General assessment}

- Absence of clinical symptoms. ${ }^{495354}$

- Absence of pain or tenderness during muscle palpation. ${ }^{15} 495486107$

- Absence of pain on passive and active stretching. ${ }^{15} 108$

- Absence of pain on isometric, concentric and eccentric contraction. ${ }^{15}$

- Completion of the prescribed rehabilitation programme. ${ }^{86}$

- MRI and US imaging assessment respecting points specified in 'The role of imaging in the RTT and RTP decision-making process' section. ${ }^{84-89}$
- Subjective feelings of the player taken into account (ie, assess levels of anxiety, apprehension, fear of failure and/or fear of reinjury). ${ }^{375494-97}$

\section{Specific assessment}

- Passive straight leg raise test. ${ }^{54} 108-110$

- Dynamic flexibility $\mathrm{H}$ test. ${ }^{111}$

Laboratory tests for RTT

The following are the laboratory tests recommended prior to RTT:

- Evaluation of hamstring muscle strength by dynamometric tests (isometric, isotonic and isokinetic tests)..$^{54} 85112113$ The basic principles for the administration of dynamometric tests are shown in table 3 .

Field tests for RTT

The following are the field tests we recommended to determine readiness to RTT after hamstring strain:

- Illinois Agility Test. ${ }^{24} 25$ 114-116

- Braking test. ${ }^{2425}$

- Backward running. ${ }^{117}$

No previous validation studies were identified on the use of field tests to inform RTT and RTP. However, we considered an RTP test checklist for athletes who suffered a lower extremity injury set out in a 2013 Delphi study. ${ }^{118}$ The tests were recommended based on expert opinions (GRADE evidence level V). Furthermore, the Illinois Agility Test is an asymmetric test ${ }^{2425114-116}$; thus, we recommend execution in its modified format formulated by Rouissi et $a l^{119}$

\section{RTP tests}

The RTP decisions are based on performance evaluation, and therefore chronologically follow the RTT decision-making process. We recommend the following RTP specific guidelines:

- The data acquisition period must start from the first day of RTT and include a period of at least 7-10 days.

- During this period, the training sessions should be systematically recorded via GPS technology.

- It is necessary to identify several 'typical' sessions from the last preinjury week and from the period following the RTT on which to base a return to normal function.

The three evaluation categories are mentioned in the 'The RTP decision-making process' section. ${ }^{57-59}$

The reference value, below which the positive judgement for RTP is postponed, is arbitrarily set at a maximum difference of $10 \%$ between preinjury data and the data recorded during the acquisition period following RTT.

Furthermore, regarding aerobic fitness, we advise the player regains a $\mathrm{VO}_{2 \max }$ value equal to at least $90 \%$ of their preinjury level.

\section{RTT and RTP decisions following quadriceps injuries Epidemiology}

In soccer, the majority ( $88 \%)$ of quadriceps femoris injuries involve the rectus femoris. ${ }^{67}$ The risk of suffering from this type of injury is higher during competition than 
Table 3 Basic principles for the administration of dynamometric (isometric, isotonic and isokinetic) tests

\begin{tabular}{|c|c|c|}
\hline Isometric tests ${ }^{147-149}$ & Isotonic tests $^{147150-152}$ & Isokinetic tests 4285112113153 \\
\hline $\begin{array}{l}\text { Biomechanically isolate the } \\
\text { muscle group to be tested. }\end{array}$ & $\begin{array}{l}\text { Biomechanically isolate the } \\
\text { muscle group to be tested. }\end{array}$ & Biomechanically isolate the muscle group to be tested. \\
\hline Standardise the lever arm. & $\begin{array}{l}\text { Standardise the lever arm and } \\
\text { ROM. }\end{array}$ & Standardise the lever arm and ROM. \\
\hline $\begin{array}{l}\text { Apply an isometric contraction } \\
\text { of progressive intensity for a } \\
\text { duration of between } 3 \mathrm{sec} \text { and } \\
5 \mathrm{sec} \text {. }\end{array}$ & $\begin{array}{l}\text { Apply the maximal speed } \\
\text { during the movement. }\end{array}$ & $\begin{array}{l}\text { Align the centre of rotation of the joint with that of the } \\
\text { mechanical device. }\end{array}$ \\
\hline $\begin{array}{l}\text { Encourage the patient during } \\
\text { the test. }\end{array}$ & $\begin{array}{l}\text { Encourage the patient during } \\
\text { the test. }\end{array}$ & Encourage the patient during the test. \\
\hline Consider the peak value. & $\begin{array}{l}\text { Consider both average and } \\
\text { peak value. }\end{array}$ & $\begin{array}{l}\text { Consider the average value, avoiding the so-called 'peak } \\
\text { artifact'. }\end{array}$ \\
\hline $\begin{array}{l}\text { Check for any pain symptoms } \\
\text { with VAS. }\end{array}$ & $\begin{array}{l}\text { Check for any pain symptoms } \\
\text { with VAS. }\end{array}$ & Check for any pain symptoms with VAS. \\
\hline $\begin{array}{l}\text { Stop the test in the presence } \\
\text { of severe pain }(V A S>3) \text {. }\end{array}$ & $\begin{array}{l}\text { Stop the test in the presence of } \\
\text { severe pain }(V A S>3) \text {. }\end{array}$ & Stop the test in the presence of severe pain (VAS $>3$ ). \\
\hline $\begin{array}{l}\text { The dynamometric values } \\
\text { must be } \geq 90 \% \text { of the } \\
\text { prelesion values or } \geq 90 \% \text { of } \\
\text { the contralateral limb values. }\end{array}$ & $\begin{array}{l}\text { The dynamometric values } \\
\text { must be } \geq 90 \% \text { of the prelesion } \\
\text { values or } \geq 90 \% \text { of the } \\
\text { contralateral limb values. }\end{array}$ & $\begin{array}{l}\text { Perform one set of } 6-10 \text { repetitions at low speed }(30 \% \\
\mathrm{s}-60 \% \mathrm{~s}) \text { and one set at high speed }(>300 \% \mathrm{~s})\end{array}$ \\
\hline
\end{tabular}

Perform at least one eccentric test at $60 \%$ s or $30 \%$ s.

Consider the value of the joint angle corresponding to the peak force production.

Consider the values of the mechanical work.

Consider the shape of the force curve.

Consider the value of the ratio of HS (concentric modality) to $Q$ (concentric modality), and the value of the ratio $H S$ (eccentric modality) to $Q$ (concentric modality).

Perform the tests observing an adequate recovery between the sets ( 2-3 min).

The dynamometric values must be $\geq>90 \%$ of the pre-lesion values or $\geq>90 \%$ of the contralateral limb values

ROM, range of motion; VAS, Visual Analogue Scale.

training ( 1.1 vs 0.3 per 1000 hours of exposure $)^{6-120} ; 62 \%$ of rectus femoris lesions are recorded during the first half of the match, and the peak risk is observed between the 16 th and 45 th minutes of play. ${ }^{6120}$ The most common mechanism of injury is during the kicking motion ( $\sim 28 \%$ of injuries). The rate of reinjury is approximately $13 \%,{ }^{121-123}$ and a team of 25 players should expect on average three lesions of the rectus femoris per season, resulting in a total time loss of around 50 days. 67

Clinical and imaging assessments for RTT

We recommend the following clinical and imaging assessments for RTT following quadriceps injury:

\section{General assessment}

- The same conditions specified for hamstring lesions hold true.

\section{Specific assessment}

- Passive quadriceps stretch test. ${ }^{108124}$

Laboratory tests for RTT

After quadriceps injury, the following are the laboratory tests for RTT recommended by CC:

- Quadriceps muscles strength assessed by dynamometric tests. 5485112113

- Synchro plates test. $^{113}$ 
Field tests for RTT

The following are the field tests recommended prior to RTT following quadriceps injury:

- Illinois Agility Test. ${ }^{24} 25114115$

- Braking test. ${ }^{2425}$

- Kicking test. ${ }^{2425}$

RTP tests

- The same conditions specified for hamstring lesions hold true.

\section{RTT and RTP decisions following adductor injuries Epidemiology}

Adductor injuries account for $23 \%$ of all muscle injuries in soccer. ${ }^{125} 126$ They occur most frequently in the 22-30years age group and reinjury rates are reported to be as high as $18 \% .{ }^{125} 126$ Previous injury and a history of reduced adductor muscle strength have been identified as risk factors for adductor injury. ${ }^{127}$ Amateur soccer players with adductor weakness are four times more prone to adductor injury. ${ }^{126}$

Clinical and imaging assessments for RTT

The following are the clinical and imaging assessments prior to RTT recommended by CC following adductor injury:

\section{General assessment}

- The same conditions specified for hamstrings and quadriceps lesions hold true.

\section{Specific assessment}

- Pubic stress test. ${ }^{113} 128129$

- Resisted hip adduction test. ${ }^{112} 127128$

- Squeeze test. ${ }^{113} 130-133$

- Adductor passive stretching test. ${ }^{108} 134$

Laboratory tests for RTT

The following are the recommended laboratory tests for RTT following adductor injury:

- Adductor muscles strength assessed by dynamometric tests. $^{54} 85112113$

Field tests for RTT

The following are the field tests for RTT recommended by CC following adductor injury:

- Kicking test. ${ }^{113}$

- Carioca test. ${ }^{135} 136$

RTP tests

- The same conditions outlined for hamstrings and quadriceps lesions hold true.

\section{RTT and RTP decisions following soleus-gastrocnemius injuries \\ Epidemiology}

Soleus-gastrocnemius (calf) injuries are common across sports involving high-speed running, high total running loads and high number of accelerations/decelerations. Calf injuries are observed frequently when a player is fatigued. Football match play incidences of 0.84 per 1000 hours of exposure have been recorded. ${ }^{137138}$ Calf injuries cause greater time loss per incident ${ }^{138}$ and are more likely to occur during critical periods of competition (eg, end of the season in soccer) ${ }^{139}$ Older soccer players (above $25.8 \pm 4.5$ years) demonstrate an almost twofold increase in the rate of calf injury (HR, 1.93; $95 \%$ CI 1.38 to 2.71$).{ }^{6}$ Age and a history of calf strain are the strongest risk factors for suffering future calf injury. ${ }^{67}$

\section{Clinical and imaging assessments for RTT}

The following are the clinical and imaging assessments prior to RTT recommended by CC following calf injury:

\section{General assessment}

- The same conditions specified for the hamstrings, quadriceps and adductor lesions hold true.

Specific assessment

- Heel-raise test. ${ }^{140} 141$

- Ankle flexibility test. ${ }^{142} 143$

Laboratory tests for RTT

The following are the laboratory tests prior to RTT recommended by CC following calf injury:

- Soleus-gastrocnemius muscles strength assessed by dynamometric tests. ${ }^{53} 84111112$

- Synchro plates test. ${ }^{113}$

- Drop jump test. ${ }^{144-146}$

Field tests for RTT

The following is the field test for RTT recommended by CC following calf injury:

- Illinois Agility Test. ${ }^{24} 25$ 114-116

RTP tests

- The same conditions specified for the hamstrings, quadriceps and adductor lesions hold true.

\section{SUMMARY AND CONCLUSION}

The Italian CC incorporated a cross-professional group of established clinician and academics from various backgrounds. The diversity of the group provided a large number of experiential-based viewpoints to be taken into account. The CC recommendations are summarised as follows:

1. The appropriateness of the term RTP and the concepts of RTT were reformulated as RTT signifying a return to sports practice with possible restrictions, and RTP a return to training and competition without restriction.

2. The general and specific criteria concerning RTT and RTP decision were identified, discussed and approved.

3. The four main muscle groups (hamstrings, quadriceps, adductors and soleus-gastrocnemius) involved in lower limb football muscle injuries were identified and discussed. The CC approved recommendations on the following areas:

a. Clinical and imaging assessment for RTT.

b. Laboratory tests for RTT.

c. Field tests for RTT. 


\section{d. RTP tests.}

\section{FUTURE OBJECTIVES}

The CC recommends the future development and research into efficacy of the following:

- Field and laboratory tests to objectively inform RTT and RTT decisions.

- The role of imaging in the decision-making processes for RTT and RTP.

\section{Author affiliations}

${ }^{1}$ Qatar Orthopaedic and Sports Medicine Hospital, Doha, Qatar

${ }^{2}$ Humanitas Clinical Institute, Rozzano, , Italy

${ }^{3} \mathrm{FC}$ Internazionale Milano, Milano, Milano, Italy

${ }^{4}$ Department of Biomedical Sciences for Health, Università degli Studi di Milano,

Milano, Italy

${ }^{5}$ Centro Traumatologico Ortopedico, Torino, , Italy

${ }^{6}$ Universita degli Studi di Milano, Milano, Italy

${ }^{7}$ UOS Angiografia e Radiologia Interventistica, Ospedale delle Apuane, Massa

Carrara, Massa Carrara, Italy

${ }^{8}$ Istituto Clinico Villa Aprica, Como, Italy

${ }^{9}$ Istituto Clinico Sant'Anna, Brescia, Italy

${ }^{10}$ Kinemove Rehabilitation Center, Pontremoli, Italy

${ }^{11}$ Feralpisalò Srl, Salò, Brescia, Italy

${ }^{12}$ Atalanta BC, Bergamo, Italy

${ }^{13}$ Dipartimento di Scienze Biomediche e Neuromotorie, Università Bologna, Bologna, Italy

${ }^{14}$ Brescia Calcio, Brescia, Italy

${ }^{15}$ US Giana Erminio, Gorgonzola, Milano, Italy

${ }^{16}$ Ospedale Koelliker, Torino, Italy

${ }^{17}$ Istituto di Medicina dello Sport di Torino, Torino, Italy

${ }^{18}$ Università Vita-Salute San Raffaele, Milano, Italy

${ }^{19}$ Azienda Ospedaliera di Rilievo Nazionale "Cardarelli", Napoli, Italy

${ }^{20}$ Paris St Germain FC, Paris, France

${ }^{21}$ Physiotherapy, Studio Riabilita, Civitanova Marche, Italy

${ }^{22}$ Universita Campus Bio-Medico di Roma, Roma, Italy

${ }^{23}$ University Hospital of Padova, Padua, Italy

${ }^{24}$ Azienda USL Toscana nord ovest Sede di Lucca, Lucca, Italy

${ }^{25}$ DXBone Fifa Medical Center of Excellence, Dubai, UAE

${ }^{26}$ Ente Ospedaliero Ospedali Galliera, Genova, Italy

${ }^{27}$ Dipartimento di Scienze Mediche di Base, Neuroscienze e Organi di Senso, Università di Bari, Bari, Italy

${ }^{28}$ FIFA Medical Centre of Excellence, Bologna, Isokinetic Medical Group, Bologna, Italy

${ }^{29}$ Bologna FC, Bologna, Italy

${ }^{30}$ Universita degli Studi di Brescia, Brescia, Italy

${ }^{31}$ Universita degli Studi Gabriele d'Annunzio Chieti e Pescara, Chieti, Italy

${ }^{32} 0$ spedale SS Annunziata, Chieti, Italy

${ }^{33}$ Parma Calcio, Parma, Italy

${ }^{34}$ Studio Radiologico Pasta, Parma, Italy

${ }^{35}$ Centro Kinetik, Rogno (BG), Italy

${ }^{36}$ Istituto Clinico San Rocco, Ome, Italy

${ }^{37}$ Universita degli Studi di Foggia, Foggia, Italy

${ }^{38}$ Studio FKT Tenconi, Genova, Italy

${ }^{39}$ Centro Diagnostico Apuano, Carrara, Italy

${ }^{40}$ Ospedale San Francesco d'Assisi, Oliveto Citra, Italy

${ }^{41}$ Universita Cattolica del Sacro Cuore, Milano, Italy

${ }^{42}$ Universita degli Studi del Molise, Campobasso, Italy

${ }^{43}$ Villa Maria Cecilia, Cotignola, Italy

${ }^{44}$ Physio Traininig, Brescia, Italy

${ }^{45}$ Research Lab, National Center of Science and Sports Medicine Tunis, Tunis, Tunisia

Acknowledgements The authors wish to thank the Italian Society of Arthroscopy (SIA) for their support in the logistics and bureaucratic organisation of the CC.

Contributors The authors gave final approval of the version to be submitted.
Funding The authors have not declared a specific grant for this research from any funding agency in the public, commercial or not-for-profit sectors.

Competing interests None declared.

Patient consent for publication Not required.

Provenance and peer review Not commissioned; externally peer reviewed.

Data availability statement All data relevant to the study are included in the article or uploaded as supplementary information.

Open access This is an open access article distributed in accordance with the Creative Commons Attribution Non Commercial (CC BY-NC 4.0) license, which permits others to distribute, remix, adapt, build upon this work non-commercially, and license their derivative works on different terms, provided the original work is properly cited, appropriate credit is given, any changes made indicated, and the use is non-commercial. See: http://creativecommons.org/licenses/by-nc/4.0/.

\section{ORCID iDs}

Alessandro Corsini http://orcid.org/0000-0001-5793-3221

Luca Pulici http://orcid.org/0000-0002-8911-1297

\section{REFERENCES}

1 Hallén A, Ekstrand J. Return to play following muscle injuries in professional footballers. J Sports Sci 2014;32:1229-36.

2 Crema MD, Guermazi A, Tol JL, et al. Acute hamstring injury in football players: association between anatomical location and extent of injury-A large single-center MRI report. J Sci Med Sport 2016;19:317-22.

3 Waldén $\mathrm{M}$, Hägglund $\mathrm{M}$, Bengtsson $\mathrm{H}$, et al. Perspectives in football medicine. Unfallchirurg 2018;121:470-4.

4 Árnason Á, Sigurdsson SB, Gudmundsson Á, et al. Risk factors for injuries in football. Am J Sports Med 2004;32(1_suppl):5-16.

5 Eirale $\mathrm{C}$, Tol JL, Faroog $\mathrm{A}$, et al. Low injury rate strongly correlates with team success in Qatari professional football. Br J Sports Med 2013;47:807-8.

6 Hägglund M, Waldén M, Magnusson $\mathrm{H}$, et al. Injuries affect team performance negatively in professional football: an 11-year followup of the UEFA champions League injury study. Br J Sports Med 2013;47:738-42.

7 Hägglund M, Waldén M, Ekstrand J. Risk factors for lower extremity muscle injury in professional soccer: the UEFA injury study. Am J Sports Med 2013;41:327-35.

8 Ardern CL, Glasgow P, Schneiders A, et al. 2016 consensus statement on return to sport from the first world Congress in sports physical therapy, Bern. Br J Sports Med 2016;50:853-64.

9 Ardern CL, Bizzini M, Bahr R. It is time for consensus on return to play after injury: five key questions. $\mathrm{Br} J$ Sports Med 2016;50:506-8.

10 Ardern CL, Khan KM. The old knee in the young athlete: knowns and unknowns in the return to play conversation. Br J Sports Med 2016;50:505-6.

11 Dijkstra HP, Pollock N, Chakraverty R, et al. Return to play in elite sport: a shared decision-making process. Br J Sports Med 2017;51:419-20.

12 Weiler R. Unknown unknowns and lessons from non-operative rehabilitation and return to play of a complete anterior cruciate ligament injury in English premier League football. Br J Sports Med 2016;50:261-2.

13 Huguet A, Hayden JA, Stinson J, et al. Judging the quality of evidence in reviews of prognostic factor research: adapting the grade framework. Syst Rev 2013;2:71.

14 Volpi P, Bisciotti GN. The hamstring muscles: anatomy, biomechanics and risk injury. Med Sport 2016;69:297-307.

15 Bisciotti GN, Volpi P, Amato M, et al. Italian consensus conference on guidelines for conservative treatment on lower limb muscle injuries in athlete. BMJ Open Sport Exerc Med 2018;4:e000323.

16 van der Horst N, Backx F, Goedhart EA, et al. Return to play after hamstring injuries in football (soccer): a worldwide Delph procedure regarding definition, medical criteria and decisionmaking. Br J Sports Med 2017;51:1583-91.

17 van der Horst N, van de Hoef S, Reurink G, et al. Return to play after hamstring injuries: a qualitative systematic review of definitions and criteria. Sports Med 2016;46:899-912.

18 Griffin DR, Dickenson EJ, O'Donnell J, et al. The Warwick agreement on femoroacetabular impingement syndrome (FAl syndrome): an international consensus statement. $\mathrm{Br} J$ Sports Med 2016;50:1169-76. 
19 Bisciotti GN, Volpi P, Zini R, et al. Groin pain syndrome Italian consensus conference on terminology, clinical evaluation and imaging assessment in groin pain in athlete. BMJ Open Sport Exerc Med 2016;2:e000142. Nov.

20 Vanbelle S, Lesaffre E. Modeling agreement on bounded scales. Stat Methods Med Res 2018;27:3460-3477.

21 Herring SA, Bergfeld JA, Boyd J, et al. The team physician and return-to-play issues: a consensus statement. Med Sci Sports Exerc 2002;34:1212-4.

22 Herring SA, Kibler WB, Putukian M. The team physician and the return-to-play decision: a consensus statement-2012 update. Med Sci Sports Exerc 2012;44:2446-8.

23 Herring SA, Kibler WB, Putukian M. Team physician consensus statement: 2013 update. Med Sci Sports Exerc 2013;45:1618-22.

24 Bisciotti GN. Return to play after a muscle lesion. In: Volpi P, ed. Arthroscopy in sport. Springer Edition, 2015.

25 Bisciotti GN, Volpi P. Return to play. In: Volpi P, ed. Football doctor manual. Trento: Edra Edition, 2018: 247-59.

26 Bizzini M, Hancock D, Impellizzeri F. Suggestions from the field for return to sports participation following anterior cruciate ligament reconstruction: soccer. J Orthop Sports Phys Ther 2012;42:304-12.

27 Bizzini M, Silvers HJ. Return to competitive football after major knee surgery: more questions than answers? J Sports Sci 2014;32:1209-16.

28 Shrier I. Strategic assessment of risk and risk tolerance (StARRT) framework for return-to-play decision-making. Br J Sports Med 2015;49:1311-5.

29 Creighton DW, Shrier I, Shultz R, et al. Return-to-play in sport: a decision-based model. Clin J Sport Med 2010;20:379-85.

30 Saal JA. Common American football injuries. Sports Med 1991;12:132-47.

31 Cantu RC. Cervical spine injuries in the athlete. Semin Neurol 2000;20:173-8

32 Sjøgaard G, Søgaard K. Muscle activity pattern dependent pain development and alleviation. J Electromyogr Kinesiol 2014;24:789-94.

33 Curl LA. Return to sport following elbow surgery. Clin Sports Med 2004;23:353-66.

34 Drake DF, Nadler SF, Chou LH, et al. Sports and performing arts medicine. 4. traumatic injuries in sports. Arch Phys Med Rehabil 2004;85(3 Suppl 1):S67-S71.

35 Eck JC, Riley LH. Return to play after lumbar spine conditions and surgeries. Clin Sports Med 2004;23:367-79.

36 Lord J, Winell JJ. Overuse injuries in pediatric athletes. Curr Opin Pediatr 2004;16:47-50.

37 McCarty EC, Ritchie P, Gill HS, et al. Shoulder instability: return to play. Clin Sports Med 2004;23:335-51.

38 Park HB, Lin SK, Yokota A, et al. Return to play for rotator cuff injuries and superior labrum anterior posterior (slap) lesions. Clin Sports Med 2004;23:321-34.

39 Dimberg EL, Burns TM. Management of common neurologic conditions in sports. Clin Sports Med 2005;24:637-62.

40 Kaeding CC, Yu JR, Wright R, et al. Management and return to play of stress fractures. Clin J Sport Med 2005;15:442-7.

41 Kovacic J, Bergfeld J. Return to play issues in upper extremity injuries. Clin J Sport Med 2005;15:448-52.

42 Orchard J, Best TM, Verrall GM. Return to play following muscle strains. Clin J Sport Med 2005;15:436-41.

43 Burnett MG, Sonntag VKH. Return to contact sports after spinal surgery. Neurosurg Focus 2006;21:1-3.

44 Diehl JJ, Best TM, Kaeding CC. Classification and return-to-play considerations for stress fractures. Clin Sports Med 2006;25:17-28.

45 Kuhn JE. Treating the initial anterior shoulder dislocation--an evidence-based medicine approach. Sports Med Arthrosc Rev 2006;14:192-8.

46 Smurawa T, Congeni J. Return-to-play decisions in the adolescent athlete: how to decide. Pediatr Ann 2007;36:746-51. 750-741.

47 Krabak B, Kennedy DJ. Functional rehabilitation of lumbar spine injuries in the athlete. Sports Med Arthrosc Rev 2008;16:47-54.

48 Miller MD, Arciero RA, Cooper DE, et al. Doc, when can He go back in the game? Instr Course Lect 2009;58:437-43.

49 Kvist J. Rehabilitation following anterior cruciate ligament injury: current recommendations for sport participation. Sports Med 2004;34:296-80.

50 Eddy D, Congeni J, Loud K. A review of spine injuries and return to play. Clin J Sport Med 2005;15:453-8.

51 Dunn IF, Proctor MR, Day AL. Lumbar spine injuries in athletes. Neurosurg Focus 2006;21:1-5.

52 Elias I, Pahl MA, Zoga AC, et al. Recurrent burner syndrome due to presumed cervical spine osteoblastoma in a collision sport athlete a case report. J Brachial Plex Peripher Nerve Inj 2007;2:13.
53 Malliaropoulos N, Isinkaye T, Tsitas K, et al. Reinjury after acute posterior thigh muscle injuries in elite track and field athletes. Am J Sports Med 2011;39:304-10.

54 Delvaux $F$, Rochcongar $P$, Bruyère $O$, et al. Return-to-play criteria after hamstring injury: actual medicine practice in professional soccer teams. J Sports Sci Med 2014;13:eCollection 2014 Sep:721-3.

55 Suarez-Arrones L, Torreño N, Requena B, et al. Match-play activity profile in professional soccer players during official games and the relationship between external and internal load. J Sports Med Phys Fitness 2015;55:1417-22.

56 Torreño N, Munguía-Izquierdo D, Coutts A, et al. Relationship between external and internal loads of professional soccer players during full matches in official games using global positioning systems and Heart-Rate technology. Int J Sports Physiol Perform 2016;11:940-6.

57 di Prampero PE, Fusi S, Sepulcri L, et al. Sprint running: a new energetic approach. J Exp Biol 2005;208:2809-16.

58 Osgnach C, Poser S, Bernardini R, et al. Energy cost and metabolic power in elite soccer: a new match analysis approach. Med Sci Sports Exerc 2010;42:170-8.

59 di Prampero PE, Botter A, Osgnach C. The energy cost of sprint running and the role of metabolic power in setting top performances. Eur J Appl Physiol 2015;115:451-69.

60 Hopper DM, Hopper JL, Elliott BC. Do selected kinanthropometric and performance variables predict injuries in female netball players? J Sports Sci 1995;13:213-22.

61 Chomiak J, Junge A, Peterson L, et al. Severe injuries in football players. influencing factors. Am J Sports Med 2000;28(5 Suppl):S58-68.

62 Ostenberg A, Roos H. Injury risk factors in female European football. A prospective study of 123 players during one season. Scand J Med Sci Sports 2000;10:279-85

63 Bell NS, Mangione TW, Hemenway D, et al. High injury rates among female army trainees: a function of gender? Am J Prev Med 2000;18:141-6.

64 Dvorak J, Junge A, Chomiak J, et al. Risk factor analysis for injuries in football players. possibilities for a prevention program. Am J Sports Med 2000;28(5 Suppl):S69-74.

65 Murphy DF, Connolly DAJ, Beynnon BD. Risk factors for lower extremity injury: a review of the literature. $\mathrm{Br} J$ Sports Med 2003;37:13-29.

66 Almeida AMde, Santos Silva PR, Pedrinelli A, et al. Aerobic fitness in professional soccer players after anterior cruciate ligament reconstruction. PLoS One 2018;13:e0194432.

67 Convertino VA. Cardiovascular consequences of bed rest: effect on maximal oxygen uptake. Med Sci Sports Exerc 1997;29:191-6.

68 Bringard A, Pogliaghi S, Adami A, et al. Cardiovascular determinants of maximal oxygen consumption in upright and supine posture at the end of prolonged bed rest in humans. Respir Physiol Neurobiol 2010;172:53-62.

69 Bellenger CR, Fuller JT, Nelson MJ, et al. Predicting maximal aerobic speed through set distance time-trials. Eur J Appl Physiol 2015;115:2593-8.

70 Heck H, Mader A, Hess G, et al. Justification of the 4-mmol// lactate threshold. Int J Sports Med 1985;06:117-30.

71 Chamari K, Hachana Y, Ahmed YB, et al. Field and laboratory testing in young elite soccer players. $\mathrm{Br} J$ Sports Med 2004;38:191-6.

72 Chamari K, Moussa-Chamari I, Boussaïdi L, et al. Appropriate interpretation of aerobic capacity: allometric scaling in adult and young soccer players. Br J Sports Med 2005;39:97-101.

73 Aandstad A, Hageberg R. Reliability and validity of a maximal treadmill test for predicting aerobic fitness in Norwegian prospective soldiers. Mil Med 2019;184:e245-52.

74 M Badawy M, I Muaidi Q. Aerobic profile during high-intensity performance in professional Saudi athletes. Pak J Biol Sci 2018;21:24-8.

75 Blanch P, Gabbett TJ. Has the athlete trained enough to return to play safely? The acute:chronic workload ratio permits clinicians to quantify a player's risk of subsequent injury. Br J Sports Med 2016;50:471-5.

76 Lolli L, Batterham AM, Hawkins R, et al. The acute-to-chronic workload ratio: an inaccurate scaling index for an unnecessary normalisation process? Br J Sports Med 2018. doi:10.1136/ bjsports-2017-098884. [Epub ahead of print: 13 Jun 2018].

77 Lolli L, Batterham AM, Hawkins R, et al. Mathematical coupling causes spurious correlation within the conventional acuteto-chronic workload ratio calculations. Br J Sports Med 2019;53:921-2. 
78 Fournier-Farley C, Lamontagne M, Gendron P, et al. Determinants of return to play after the Nonoperative management of hamstring injuries in athletes: a systematic review. Am J Sports Med 2016:44:2166-72.

79 Wangensteen A, Almusa E, Boukarroum S, et al. Mri does not add value over and above patient history and clinical examination in predicting time to return to sport after acute hamstring injuries: a prospective cohort of 180 male athletes. Br J Sports Med 2015;49:1579-87.

80 Jacobsen P, Witvrouw E, Muxart P, et al. A combination of initial and follow-up physiotherapist examination predicts physiciandetermined time to return to play after hamstring injury, with no added value of MRI. Br J Sports Med 2016;50:431-9.

81 Pollock N, Patel A, Chakraverty J, et al. Time to return to full training is delayed and recurrence rate is higher in intratendinous ('c') acute hamstring injury in elite track and field athletes: clinical application of the British Athletics Muscle Injury Classification. Br J Sports Med 2016;50:305-10.

82 Moen MH, Reurink G, Weir A, et al. Predicting return to play after hamstring injuries. Br J Sports Med 2014;48:1358-63.

83 Reurink G, Brilman EG, de Vos R-J, et al. Magnetic resonance imaging in acute hamstring injury: can we provide a return to play prognosis? Sports Med 2015;45:133-46.

84 Connell DA, Schneider-Kolsky ME, Hoving JL, et al. Longitudinal study comparing sonographic and MRI assessments of acute and healing hamstring injuries. AJR Am J Roentgenol 2004;183:975-84.

85 Sanfilippo JL, Silder A, Sherry MA, et al. Hamstring strength and morphology progression after return to sport from injury. Med Sci Sports Exerc 2013;45:448-54.

86 Reurink G, Goudswaard GJ, Tol JL, et al. Mri observations at return to play of clinically recovered hamstring injuries. Br J Sports Med 2014;48:1370-6.

87 Bedair HS, Karthikeyan T, Quintero A, et al. Angiotensin II receptor blockade administered after injury improves muscle regeneration and decreases fibrosis in normal skeletal muscle. Am J Sports Med 2008;36:1548-54.

88 Gharaibeh B, Chun-Lansinger Y, Hagen T, et al. Biological approaches to improve skeletal muscle healing after injury and disease. Birth Defects Res C Embryo Today 2012;96:82-94.

89 Slavotinek JP. Muscle injury: the role of imaging in prognostic assignment and monitoring of muscle repair. Semin Musculoskelet Radiol 2010;14:194-200.

90 Wiese-bjornstal DM, Smith AM, Shaffer SM, et al. An integrated model of response to sport injury: psychological and sociological dynamics. J App/ Sport Psychol 1998;10:46-69.

91 Atkins E, Colville G, John M. A 'biopsychosocial' model for recovery: a grounded theory study of families' journeys after a Paediatric Intensive Care Admission. Intensive Crit Care Nurs 2012;28:133-40.

92 Ayers DC, Franklin PD, Ring DC. The role of emotional health in functional outcomes after orthopaedic surgery: extending the biopsychosocial model to orthopaedics. J Bone Joint Surg Am 2013;95:1-7.

93 Pincus T, Kent P, Bronfort G, et al. Twenty-Five years with the biopsychosocial model of low back pain-is it time to celebrate? A report from the twelfth international forum for primary care research on low back pain. Spine 2013;38:2118-23.

94 Bauman J. Returning to play: the mind does matter. Clin J Sport Med 2005;15:432-5.

95 Glazer DD. Development and preliminary validation of the InjuryPsychological readiness to return to sport (I-PRRS) scale. J Athl Train 2009:44:185-9.

96 Langford JL, Webster KE, Feller JA. A prospective longitudinal study to assess psychological changes following anterior cruciate ligament reconstruction surgery. Br J Sports Med 2009;43:377-8.

97 Clover J, Wall J. Return-to-Play criteria following sports injury. Clin Sports Med 2010;29:169-75.

98 McFarland EG. Return to play. Clin Sports Med 2004;23:xv-xxiii.

99 Best TM, Brolinson PG. Return to play: the sideline dilemma. Clin J Sport Med 2005;15:403-4.

100 Tucker AM. Ethics and the professional team physician. Clin Sports Med 2004;23:227-41.

101 Verrall GM, Brukner PD, Seward HG. 6. doctor on the sidelines. Med J Aust 2006;184:244-8.

102 Tator $\mathrm{CH}$. Recognition and management of spinal cord injuries in sports and recreation. Neurol Clin 2008;26:79-88.

103 Matheson GO, Shultz R, Bido J, et al. Return-to-play decisions: are they the team physician's responsibility? Clin J Sport Med 2011;21:25-30

104 Maron BJ, Brown RW, McGrew CA, et al. Ethical, legal, and practical considerations impacting medical decision-making in competitive athletes. Med Sci Sports Exerc 1994;26(Supplement):S 238-S237.

105 Fuller CW, Walker J. Quantifying the functional rehabilitation of injured football players. Br J Sports Med 2006:40:151-7.

106 Ekstrand J, Waldén M, Hägglund M. Hamstring injuries have increased by $4 \%$ annually in men's professional football, since 2001: a 13-year longitudinal analysis of the UEFA Elite Club injury study. Br J Sports Med 2016;50:731-7.

107 Zambaldi M, Beasley I, Rushton A. Return to play criteria after hamstring muscle injury in professional football: a Delphi consensus study. Br J Sports Med 2017;51:1221-6.

108 Witvrouw E, Danneels L, Asselman P, et al. Muscle flexibility as a risk factor for developing muscle injuries in male professional soccer players. Am J Sports Med 2003;31:41-6. Jan-Feb.

109 Ridehalgh C, Moore A, Hough A. Sciatic nerve excursion during a modified passive straight leg raise test in asymptomatic participants and participants with spinally referred leg pain. Man Ther 2015;20:564-9.

110 Kellis E, Ellinoudis A, Kofotolis N. Hamstring elongation quantified using ultrasonography during the straight leg raise test in individuals with low back pain. Pm R 2015;7:576-83.

111 Askling CM, Nilsson J, Thorstensson A. A new hamstring test to complement the common clinical examination before return to sport after injury. Knee Surg Sports Traumatol Arthrosc 2010;18:1798-803.

112 Croisier J-L, Forthomme B, Namurois $\mathrm{M}-\mathrm{H}$, et al. Hamstring muscle strain recurrence and strength performance disorders. Am J Sports Med 2002;30:199-203.

113 Bisciotti GN, Quaglia A, Belli A, et al. Return to sports after ACL reconstruction: a new functional test protocol. Muscles Ligaments Tendons J 2016;06:499-509.

114 Raya MA, Gailey RS, Gaunaurd IA, et al. Comparison of three agility tests with male servicemembers: Edgren side step test, t-test, and Illinois Agility test. J Rehabil Res Dev 2013;50:951-60.

115 Hachana $Y$, Chaabène $H$, Nabli MA, et al. Test-Retest reliability, criterion-related validity, and minimal detectable change of the Illinois agility test in male team sport athletes. J Strength Cond Res 2013;27:2752-9.

116 Negra $\mathrm{Y}$, Chaabene $\mathrm{H}$, Hammami M, et al. Agility in young athletes: is it a different ability from speed and power? J Strength Cond Res 2017:31:727-35.

117 Brumitt J, Heiderscheit BC, Manske RC, et al. Lower extremity functional tests and risk of injury in division III collegiate athletes. Int J Sports Phys Ther 2013;8:216-27.

118 Haines S, Baker T, Donaldson M. Development of a physical performance assessment checklist for athletes who sustained a lower extremity injury in preparation for return to sport: a Delphi study. Int J Sports Phys Ther 2013;8:44-53.

119 Rouissi M, Chtara M, Berriri A, et al. Asymmetry of the modified Illinois change of direction test impacts young elite soccer players' performance. Asian J Sports Med 2016;7:e33598.

120 Bengtsson H, Ekstrand J, Hägglund M. Muscle injury rates in professional football increase with fixture congestion: an 11-year follow-up of the UEFA champions League injury study. $\mathrm{Br} J$ Sports Med 2013;47:743-7.

121 Deehan DJ, Bell K, McCaskie AW. Adolescent musculoskeletal injuries in a football Academy. J Bone Joint Surg Br 2007;89B:5-8

122 Fousekis K, Tsepis E, Poulmedis P, et al. Intrinsic risk factors of non-contact quadriceps and hamstring strains in soccer: a prospective study of 100 professional players. Br J Sports Med 2011:45:709-14.

123 Mueller-Wohlfahrt HW, Ueblacker P, Haensel L, et al. Muscle inh+juries in sports. Thieme Editions. New York 2013pp:42-3.

124 Bouvier T, Opplert J, Cometti C, et al. Acute effects of static stretching on muscle-tendon mechanics of quadriceps and plantar flexor muscles. Eur J Appl Physiol 2017;117:1309-15.

125 Ekstrand J, Hägglund M, Waldén M. Injury incidence and injury patterns in professional football: the UEFA injury study. Br J Sports Med 2011b;45:553-8.

126 Ekstrand J, Hägglund M, Waldén M. Epidemiology of muscle injuries in professional football (soccer). Am J Sports Med 2011a;39:1226-32.

127 Engebretsen AH, Myklebust G, Holme I, et al. Intrinsic risk factors for groin injuries among male soccer players: a prospective cohort study. Am J Sports Med 2010;38:2051-7.

128 Hogan A, Lovell G. The groin pain provocation test. In: Brown A, ed. 4thWorld Football Symposium Conference Proceedings. London: Routledge, 1998.

129 Bisciotti GN. La tendinopatia degli adduttoria NEL calciatore quando IL ritorno alla corsa? Strength \& Conditioning 2013;5:11-16. 
130 Delahunt E, McEntee BL, Kennelly C, et al. Intrarater reliability of the adductor squeeze test in gaelic games athletes. J Athl Train 2011;46:241-5. May-Jun.

131 Delahunt E, Kennelly C, McEntee BL, et al. The thigh adductor squeeze test: $45^{\circ}$ of hip flexion as the optimal test position for eliciting adductor muscle activity and maximum pressure values. Man Ther 2011;16:476-80.

132 Hodgson L, Hignett T, Edwards K. Normative adductor squeeze tests scores in rugby. Phys Ther Sport 2015;16:93-7.

133 Nevin F, Delahunt E. Adductor squeeze test values and hip joint range of motion in Gaelic football athletes with longstanding groin pain. J Sci Med Sport 2014;17:155-9.

134 Atkinson HDE, Johal P, Falworth MS, et al. Adductor tenotomy: its role in the management of sports-related chronic groin pain. Arch Orthop Trauma Surg 2010;130:965-70.

135 Kong DH, Yang SJ, Ha JK, et al. Validation of functional performance tests after anterior cruciate ligament reconstruction. Knee Surg Relat Res 2012;24:40-5.

136 Jang SH, Kim JG, Ha JK, et al. Functional performance tests as indicators of returning to sports after anterior cruciate ligament reconstruction. Knee 2014;21:95-101.

137 Orchard J, Seward H. Afl injury report Australian football League; 2014: 1-20.

138 Carling C, Le Gall F, Orhant E. A four-season prospective study of muscle strain reoccurrences in a professional football Club. Res Sports Med 2011;19:92-102.

139 Mallo J, González P, Veiga S, et al. Injury incidence in a Spanish sub-elite professional football team: a prospective study during four consecutive seasons. J Sports Sci Med 2011;10:731-6.

140 Möller M, Lind K, Styf J, et al. The reliability of isokinetic testing of the ankle joint and a heel-raise test for endurance. Knee Surg Sports Traumatol Arthrosc 2005;13:60-71.

141 Harris-Love MO, Shrader JA, Davenport TE, et al. Are repeated single-limb heel raises and manual muscle testing associated with peak plantar-flexor force in people with inclusion body myositis? Phys Ther 2014;94:543-52.

142 Baumach SF, Braunstein M, Regauer M, et al. Diagnosis of Musculus Gastrocnemius Tightness - Key Factors for the Clinical Examination. J Vis Exp 2016;113.
143 Baumbach SF, Braunstein M, Seeliger F, et al. Ankle dorsiflexion: what is normal? development of a decision pathway for diagnosing impaired ankle dorsiflexion and M. gastrocnemius tightness. Arch Orthop Trauma Surg 2016b;136:1203-11. Sep.

144 Silbernagel KG, Gustavsson A, Thomeé R, et al. Evaluation of lower leg function in patients with Achilles tendinopathy. Knee Surg Sports Traumatol Arthrosc 2006;14:1207-17.

145 Hewett T, Snyder-Mackler L, Spindler KP. The drop-jump screening test: difference in lower limb control by gender and effect of neuromuscular training in female athletes. Am J Sports Med 2007;35:145.

146 Powell HC, Silbernagel KG, Brorsson A, et al. Individuals post Achilles tendon rupture exhibit asymmetrical knee and ankle kinetics and loading rates during a drop countermovement jump. $J$ Orthop Sports Phys Ther 2018;48:34-43.

147 Webber SC, Porter MM. Reliability of ankle isometric, isotonic, and isokinetic strength and power testing in older women. Phys Ther 2010;90:1165-75.

148 Toonstra J, Mattacola CG. Test-Retest reliability and validity of isometric knee-flexion and -extension measurement using 3 methods of assessing muscle strength. J Sport Rehabil 2013;22.

149 Ruschel C, Haupenthal A, Jacomel GF, Fernandes Jacomel G, et al. Validity and reliability of an instrumented leg-extension machine for measuring isometric muscle strength of the knee extensors. J Sport Rehabil 2015;24:2013-122.

150 Bieler T, Magnusson SP, Christensen HE, et al. Muscle power is an important measure to detect deficits in muscle function in hip osteoarthritis: a cross-sectional study. Disabil Rehabil 2017;39:1414-21.

151 Van Driessche S, Delecluse C, Bautmans I, et al. Age-Related differences in rate of power development exceed differences in peak power. Exp Gerontol 2018b;101:95-100.

152 Van Driessche S, Van Roie E, Vanwanseele B, et al. Age-Related decline in leg-extensor power development in single- versus multijoint movements. Exp Gerontol 2018a;110:98-104. Sep.

153 Menzel H-J, Chagas MH, Szmuchrowski LA, et al. Analysis of lower limb asymmetries by isokinetic and vertical jump tests in soccer players. J Strength Cond Res 2013;27:1370-7. 